\title{
DIAGNOSTIC CUT-OFF OF PLEURAL FLUID ADENOSINE DEAMINASE (ADA) VALUE IN TUBERCULOUS PLEURAL EFFUSION
}

\author{
Smitha Sharngan ${ }^{1}$, Reshmi Sasidharan Nair², Danam Rajan ${ }^{3}$ \\ ${ }^{1}$ Assistant Insurance Medical Officer, ESI Hospital, Vadavathoor, Kottayam. \\ ${ }^{2}$ Assistant Professor, Department of Pulmonary Medicine, GMC, Trivandrum. \\ ${ }^{3}$ Assistant Professor, Department of Pulmonary Medicine, GMC, Trivandrum.
}

\begin{abstract}
BACKGROUND
ABSTRACT

Among the various aetiologies of exudative pleural effusion, tuberculosis still remains high in the list, especially in developing countries like India. Tuberculous pleural effusion is the second most common form of extrapulmonary tuberculosis, just behind lymph node tuberculosis. Establishing tuberculosis as the aetiology of pleural effusion is hence very important. Though demonstration of acid fast bacilli in pleural fluid by smear/culture or caseating granuloma in the histopathological examination of pleural biopsy are diagnostic, these are not feasible in all cases. In this context comes the diagnostic value of adenosine deaminase (ADA) in pleural fluid. This is a biochemical test done in pleural fluid, which can give a clue towards the diagnosis of tuberculous aetiology. Several studies have shown different cut-off values of ADA, above which it is considered as positive. Hence, this study was planned to find out the best cut-off value of ADA in diagnosing tuberculous pleural effusion in a tertiary care centre in Trivandrum, Kerala.
\end{abstract}

The aim of this study is to determine the best cut-off value of ADA that can diagnose tuberculous pleural effusion.

\section{MATERIALS AND METHODS}

Settings and Design- This was a descriptive study done in the Department of Pulmonary Medicine, GMC, Trivandrum. Study population included consecutive cases of exudative pleural effusion, attending the Department during the period from January 2015 to April 2016. All exudative pleural effusions during the period were taken and a total of 175 cases (80 tuberculous) were studied. A case was taken as tuberculous using defined criteria. Patients with empyema and post-traumatic effusions were excluded from the study.

Statistical Analysis- Analysis was done using SPSS version 22.0. Sensitivity and specificity of pleural fluid ADA in diagnosing tuberculosis were determined. An ROC curve was plotted to find the optimum cut-off value of ADA to predict a diagnosis of tuberculosis. This was further verified using the Youden's index.

\section{RESULTS}

A cut-off value of pleural fluid ADA of $38.3 \mathrm{U} / \mathrm{L}$ had a sensitivity of 93\% and a specificity of 97\%. Youden's index was maximum (0.89) for this value, which was taken as the optimum cut off.

\section{CONCLUSION}

Pleural fluid ADA levels were significantly higher in tuberculous pleural effusion when compared to the non-tuberculous group. The cut-off value of $38.3 \mathrm{U} / \mathrm{L}$ with the maximum Youden's index was comparable with previous studies published.

\section{KEYWORDS}

Adenosine Deaminase, Tuberculosis, Pleural Effusion.

HOW TO CITE THIS ARTICLE: Sharngan S, Nair RS, Rajan D. Diagnostic cut-off of pleural fluid adenosine deaminase (ADA) value in tuberculous pleural effusion. J. Evolution Med. Dent. Sci. 2018;7(07):838-842, DOI: 10.14260/jemds/2018/191

\section{BACKGROUND}

Pleural effusion is a common clinical problem encountered by physicians globally. They are mainly classified as exudative and transudative. Transudative effusions are often secondary to some other systemic illnesses like cardiac failure, nephrotic syndrome, cirrhosis of liver, hypoproteinaemia etc. Exudative effusions occur secondary to infections, malignancy, collagen vascular diseases etc. Among the causes of exudative pleural effusions, tuberculosis still ranks high in the list, especially in developing countries like India. Tuberculous pleural effusion

'Financial or Other Competing Interest': None.

Submission 02-01-2018, Peer Review 30-01-2018,

Acceptance 05-02-2018, Published 12-02-2018.

Corresponding Author:

Reshmi Sasidharan Nair,

Assistant Professor,

Department of Pulmonary Medicine, GMC, Trivandrum.

E-mail: reshmisathish@rediffmail.com

DOI: $10.14260 /$ jemds $/ 2018 / 191$ ond most common extrapulmonary tuberculosis just behind lymph node tuberculosis. Hence, it is very important in diagnosing tuberculosis as the aetiology of pleural effusion. Tuberculous effusions are mainly lymphocytic pleural effusions and the main differential is a malignant pleural effusion. A definitive diagnosis can be obtained if acid fast bacilli are demonstrated in pleural fluid/ pleural biopsy specimen by direct smear/ culture or if a histopathological evidence of caseating granuloma is available. This is not yielding in all cases, as the positivity of AFB in pleural fluid is very low $(5 \%-10 \%){ }^{1}$ Culture is time consuming (Yield around $36 \%$ for mycobacterium tuberculosis) and pleural biopsy is an invasive procedure. ${ }^{1}$ So it will be of great use, if there is a reliable molecular marker that can rapidly and more or less accurately differentiate tuberculous pleural effusion from non-tuberculous effusions, mainly malignant. In this context comes the value of adenosine deaminase (ADA), which is a biochemical investigation done in pleural fluid that can give a clue towards the diagnosis of tuberculosis as the aetiology of pleural effusion. Several meta-analyses have 
shown that ADA has a favourable diagnostic value in tuberculous pleural effusions. 2,3,4

ADA is an enzyme which catalyses the conversion of adenosine to inosine. It has a major role in differentiation of lymphoid cells. Its activity is high in conditions where the cellular immunity is stimulated. ${ }^{5} \mathrm{ADA}$ has two isoforms, ADA1 and 2 . ADA- 1 is found in all cells including lymphocytes and monocytes, whereas ADA- 2 is seen exclusively in monocytes. ADA-2 is the one which increases in tuberculous pleural effusion. But for practical purposes in clinical field, total ADA activity assessment is enough. Usefulness of ADA in diagnosing tuberculosis depends on the prevalence of disease in the population. In the West, where the prevalence is low positive predictive value of the test decreases, but negative predictive value is high. Hence, this can be used as an effective screening test. In India, where there is high tuberculosis prevalence, the sensitivity and specificity of ADA is high. ${ }^{6}$ Several studies have shown different cut-off values for ADA (Ranging from 30 - 100 IU/L), above which it is taken as positive. ${ }^{7}$ Hence, a study was planned in the Department of Pulmonary Medicine, Government Medical College, Trivandrum, to find out the optimum cut-off value of ADA that can diagnose tuberculous pleural effusions.

\section{MATERIALS AND METHODS}

This was a descriptive study done in the Department of Pulmonary Medicine, Government Medical College, Trivandrum, during the period from January 2015 to April 2016. The study population included all patients with exudative pleural effusion (according to Light's criteria), who attended the Department during the study period. Patients with frank empyema and post traumatic effusions were excluded from the study. After history and clinical examination, radiological evaluation with a chest $\mathrm{x}$-ray (USG chest and CT chest only in selected cases) was done in all. Pleural fluid aspiration was done in all cases and fluid analysis was done (biochemistry including ADA, microbiology and cytology). Percutaneous blind pleural biopsy was done in a few selected patients. Thoracoscopy was not done as the facility was not available in the hospital during the study period. Pleural fluid ADA was done using diazyme method in all patients to ensure uniformity in the results. Sputum for $\mathrm{AFB} /$ cytology, lymph node aspiration cytology etc. were done in indicated patients. A case was diagnosed as tuberculous pleural effusion if any one of the following was present;

- Sputum for AFB positive.

- Pleural fluid AFB smear/ culture positive.

- Histopathological or cytological evidence of tuberculosis from pleural biopsy, lymph node or other sites.

- If all were negative, a clinical and radiological picture suggestive of tuberculosis with definite improvement on anti-tuberculosis treatment was taken as diagnostic of tuberculous pleural effusion.

All the 175 cases of exudative pleural effusions who attended the Department during the study period were taken for the study, which included 80 cases with tuberculous aetiology. Institutional Ethics Committee clearance was obtained prior to the conduct of the study.

Statistical analysis was done using SPSS version 22.0. Quantitative variables were expressed as mean and standard deviation. Categorical variables were expressed as proportion.
A p-value $<0.05$ was considered statistically significant. Sensitivity and specificity of pleural fluid ADA in diagnosing tuberculosis were found out. An ROC curve was plotted to find out the optimum cut-off value of pleural fluid ADA to predict tuberculosis diagnosis. This value was further verified using Youden's index.

\section{RESULTS}

Of the 175 cases studied, 80 were diagnosed as tuberculous effusion.

The following table shows the baseline characteristics of the two groups, tuberculous and non-tuberculous. The male: female ratio was 2.3:1 among the tuberculous group and 1.7:1 among the non-tuberculous group.

\begin{tabular}{|c|c|c|}
\hline & $\begin{array}{c}\text { Tuberculous } \\
\text { Effusion } \\
\text { (N=80) }\end{array}$ & $\begin{array}{c}\text { Non-Tuberculous } \\
\text { Effusion } \\
\text { (N=95) }\end{array}$ \\
\hline Male: Female & $56: 24$ & $60: 35$ \\
\hline Mean age \pm 2 SD & $41.46 \pm 34.26$ years & $54.82 \pm 28.4$ years \\
\hline $\begin{array}{c}\text { History of } \\
\text { Diabetes } \\
\text { Mellitus }\end{array}$ & 19 & 49 \\
\hline $\begin{array}{c}\text { History of } \\
\text { Smoking }\end{array}$ & 38 & 54 \\
\hline $\begin{array}{c}\text { Smoking Index } \\
>500\end{array}$ & 0 & 4 \\
\hline
\end{tabular}

Most of the cases who were smokers had a smoking index between 300 and 400. Among the non-tuberculous group 4 cases had a smoking index more than 500 , whereas none in the tuberculous group had the index $>500$. A diagnosis of tuberculosis was made in three cases each with sputum AFB positivity and a diagnostic histopathology in blind pleural biopsy specimen. Five cases had an aspiration cytology from cervical lymph node, suggestive of tuberculosis.

The table below shows the aetiological distribution of nontuberculous pleural effusion.

\begin{tabular}{|c|c|}
\hline Diagnosis & Number of Cases \\
\hline Syn-pneumonic effusion & 60 \\
\hline Malignancy & 33 \\
\hline Connective tissue disease & 1 \\
\hline Pancreatic effusion & 1 \\
\hline
\end{tabular}

The split up of malignant effusions was as follows:

\begin{tabular}{|c|c|}
\hline Diagnosis & Number of Cases \\
\hline Metastatic adenocarcinoma & 26 \\
\hline Non-Hodgkin's lymphoma & 2 \\
\hline Plasma cell myeloma & 1 \\
\hline $\begin{array}{c}\text { Poorly differentiated squamous cell } \\
\text { carcinoma }\end{array}$ & 1 \\
\hline Poorly differentiated adenocarcinoma & 1 \\
\hline Small cell carcinoma & 1 \\
\hline $\begin{array}{c}\text { Metastasis from poorly differentiated } \\
\text { carcinoma }\end{array}$ & 1 \\
\hline
\end{tabular}

The pleural fluid was straw coloured in all cases of tuberculous pleural effusion. In non-tuberculous group, 37 had a haemorrhagic pleural fluid macroscopically. The pleural fluid differential counts showed a mean lymphocyte count of 0.906 (SD 0.106) among tuberculous pleural effusions. 
The mean ADA value was $60.09 \pm 38.36 \mathrm{IU} / \mathrm{L}$ among the cases with tuberculous effusion and $21.01 \pm 22.82 \mathrm{IU} / \mathrm{L}$ in the other group. An ROC curve plotted for pleural fluid ADA values for tuberculous pleural effusions showed an AUC of 0.977. At a cut-off value of $38.3 \mathrm{IU} / \mathrm{L}$, pleural fluid ADA showed a sensitivity of $93 \%$ and a specificity of $97 \%$ in diagnosing tuberculosis aetiology. This was further verified using Youden's index, which was maximum (0.89) at the above cutoff value.

\section{ROC Curve}

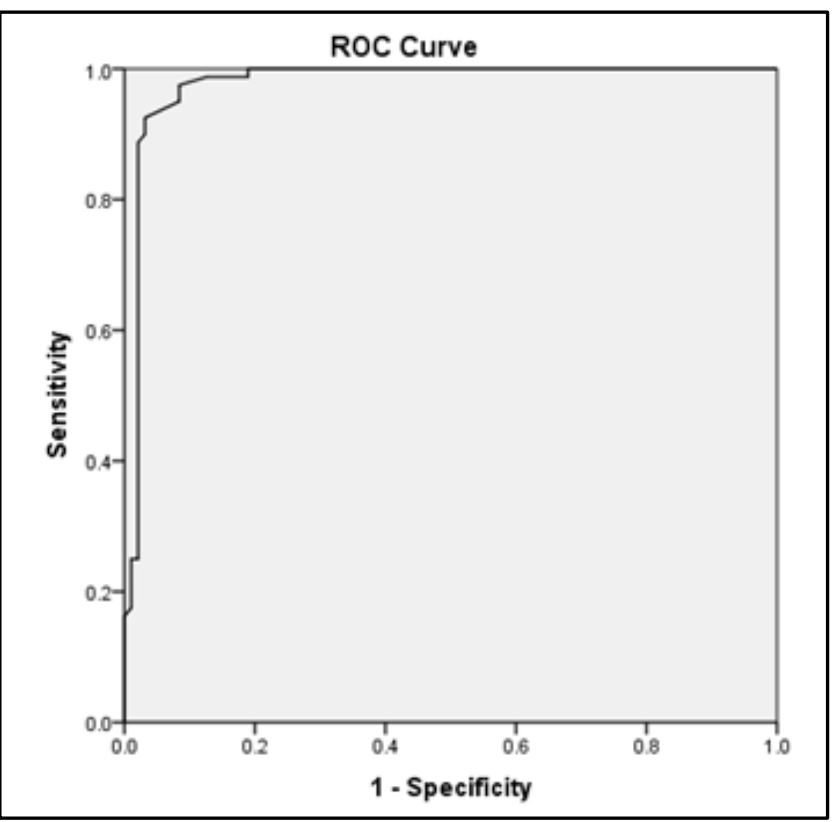

\begin{tabular}{|c|c|c|c|}
\hline Area & Standard Error & P & 95\% CI \\
\hline 0.977 & 0.012 & 0.000 & $0.954-1.000$ \\
\hline
\end{tabular}

Youden's Index

\begin{tabular}{|c|c|c|c|}
\hline $\begin{array}{c}\text { ADA Value } \\
\text { (IU/L) }\end{array}$ & $\begin{array}{c}\text { Sensitivity } \\
\text { (Sn) }\end{array}$ & $\begin{array}{c}\text { Specificity } \\
\text { (Sp) }\end{array}$ & $\begin{array}{c}\text { Youden's Index } \\
\mathbf{(} \text { (Sn+Sp) - 1 }\end{array}$ \\
\hline$>15$ & $100 \%$ & $33 \%$ & 0.33 \\
\hline$>20$ & $100 \%$ & $57 \%$ & 0.57 \\
\hline$>25$ & $100 \%$ & $77 \%$ & 0.77 \\
\hline$>30$ & $99 \%$ & $86 \%$ & 0.84 \\
\hline$>35$ & $96 \%$ & $91 \%$ & 0.87 \\
\hline$>38.3$ & $\mathbf{9 3 \%}$ & $\mathbf{9 7 \%}$ & $\mathbf{0 . 8 9}$ \\
\hline$>40$ & $90 \%$ & $97 \%$ & 0.86 \\
\hline$>45$ & $77 \%$ & $98 \%$ & 0.74 \\
\hline$>50$ & $66 \%$ & $98 \%$ & 0.64 \\
\hline$>55$ & $51 \%$ & $98 \%$ & 0.48 \\
\hline$>60$ & $42 \%$ & $98 \%$ & 0.39 \\
\hline$>65$ & $32 \%$ & $98 \%$ & 0.30 \\
\hline$>70$ & $24 \%$ & $99 \%$ & 0.23 \\
\hline$>75$ & $20 \%$ & $99 \%$ & 0.19 \\
\hline$>80$ & $17 \%$ & $100 \%$ & 0.17 \\
\hline
\end{tabular}

The sensitivity, specificity, positive predictive value, negative predictive value and diagnostic accuracy of pleural fluid ADA as a diagnostic test is given below.

\begin{tabular}{|c|c|c|c|}
\hline $\begin{array}{c}\text { Pleural Fluid } \\
\text { ADA (IU/L) }\end{array}$ & $\begin{array}{c}\text { Tuberculous } \\
\text { Effusion (N=80) }\end{array}$ & $\begin{array}{c}\text { Non- } \\
\text { Tuberculous } \\
\text { Effusion (N=95) }\end{array}$ & Total \\
\hline$\geq 38.3$ & 74 (True positive) & 3 (False positive) & 77 \\
\hline$<38.3$ & 6 (False negative) & 92 (True negative) & 98 \\
\hline
\end{tabular}

Sensitivity $=74 / 80 \times 100=92.5 \%$

Specificity $=92 / 95 \times 100=97 \%$

Positive predictive value $=74 / 77 \times 100=96 \%$

Negative predictive value $=92 / 98 \times 100=94 \%$

Diagnostic accuracy $=($ True positive + True negative $) /$ Total cases $\times 100=166 / 175 \times 100=95 \%$

\section{DISCUSSION}

The major diagnoses among non-tuberculous pleural effusions in our study were syn-pneumonic effusions and malignant effusions. One case each of connective tissue associated effusion and pancreatic effusion were also encountered. Literature also reveals a similar pattern of aetiology of pleural effusion in clinical practice. If we narrow down the cases to lymphocyte predominant pleural effusions, then the major differential will be malignant effusions. A study by Sahn SA et al says that if the fluid lymphocyte percentage is more than $85 \%$, it is very much suggestive of tuberculous pleural effusion. ${ }^{8}$ Another study by Berger HW et al shows that among tuberculous pleural effusions, only around $10 \%$ had a lymphocyte count in pleural fluid of less than $50 \% .{ }^{9}$ The mean lymphocyte ratio in tuberculous pleural effusions in our study was 0.906 (SD 0.106) and that of the non-tuberculous group was 0.204 .

The mean ADA of tuberculous pleural effusion in our study was 60.09 (SD 19.18) IU/L. Moreover, when a cut-off value of $38.3 \mathrm{IU} / \mathrm{L}$ of ADA was used, there was maximum sensitivity and specificity for the diagnosis of tuberculosis. Various studies have taken cut-off values ranging from 30 to $100 \mathrm{IU} / \mathrm{L}$ of pleural fluid ADA in diagnosing tuberculosis with varying sensitivity and specificity. ${ }^{7}$ The difference in the values may be due to the different methods used for ADA analysis, prevalence of tuberculosis in different study groups and also difference in study population characteristics. For ensuring uniformity in results, we had used the same method for analysis of ADA (diazyme method) in our study. A study done by Tay, Tee et al concluded that the cut-off level of ADA for diagnosing tuberculous pleural effusion was different in different age groups (72 IU/L in < 55 years and 26 IU/L in > 55 years' age group). ${ }^{10}$ The same study also analysed other variables that can affect the pleural fluid ADA level. Though the strongest correlation was with age, other factors like pleural fluid protein, LDH and fluid lymphocyte count also were found to influence the level of ADA.

Most studies use a cut-off value of ADA of $>40 \mathrm{IU} / \mathrm{L}$ for diagnosing tuberculous pleural effusions. Our study revealed a cut-off value of 38.3 IU/L. Another Indian study by Sharma SK et al had the cut-off of 35 IU/L for ADA, which is comparable to our value. ${ }^{11}$ When ADA values are combined with a pleural fluid lymphocyte ratio more than $50 \%$, the chances of making a diagnosis of tuberculosis are even higher. In a study done by Rahman et al in Bihar, India, pleural fluid ADA value $>50 \mathrm{IU} / \mathrm{L}$ showed a sensitivity of $97.6 \%$ and a specificity of $87.5 \%$ in diagnosing tuberculous pleural effusion. When this was combined with a pleural fluid lymphocyte ratio $>0.75$, the sensitivity increased to $100 \%$ and specificity to $92.8 \% .^{12}$ This 
was earlier established in other studies too using it as a tool for diagnosing tuberculous effusion. ${ }^{13,14,15}$ Combined use of ADA and lymphocyte- neutrophil ratio in pleural fluid was found to be more useful in diagnosing tuberculous effusion than ADA alone. The study by Antin et al showed that the pleural fluid lymphocyte ratio $>0.75$ was a significant indicator of tuberculous pleurisy when compared to other lymphocyte predominant exudative effusions. ${ }^{14}$

Making a definitive diagnosis with a gold standard is often difficult in tuberculous pleural effusion. Though we had put forward the criteria for diagnosing tuberculosis, a gold standard diagnosis was available only in eleven cases. Most of the cases had a clinical diagnosis. It is in these situations that ADA plays a helpful role. Searching the literature, we found that many of the other studies also have taken diagnostic criteria similar to ours and were not based on gold standard diagnosis alone. Lack of thoracoscopy to take pleural biopsy was a limitation of our study. Valdes L et al in his study reiterates that with the high diagnostic yield of pleural fluid ADA in regions with high prevalence of tuberculosis it would be possible to diagnose tuberculous pleural effusions without pleural biopsy. Biopsy should be reserved for patients with low ADA, a negative fluid cytology and a high suspicion of malignancy. ${ }^{16}$

The following table compares the cut-off value taken for ADA in some previous studies with ours, and the sensitivity, specificity, positive predictive value and negative predictive value for each. The mean ADA value for tuberculous effusions in these studies are also shown.

\begin{tabular}{|c|c|c|c|c|c|c|}
\hline 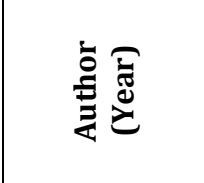 & 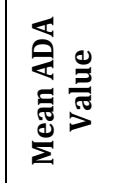 & 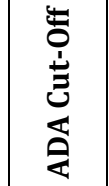 & : & 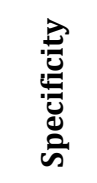 & $\frac{2}{a}$ & $\frac{2}{z}$ \\
\hline $\begin{array}{c}\text { Gupta BK } \\
(2010)^{6}\end{array}$ & $\begin{array}{c}67.34 \pm \\
22.85\end{array}$ & $\begin{array}{c}40 \\
\mathrm{U} / \mathrm{L}\end{array}$ & 92.8 & 90 & 92.86 & 90 \\
\hline $\begin{array}{c}\text { Sonone KK } \\
(2014)\end{array}$ & $\begin{array}{c}82.61 \pm \\
12.03 \\
\end{array}$ & $\begin{array}{l}33.3 \\
\mathrm{U} / \mathrm{L} \\
\end{array}$ & 93.93 & 96.69 & 96.87 & 94.11 \\
\hline $\begin{array}{l}\text { Verma SK } \\
(2008)^{17}\end{array}$ & --- & $\begin{array}{c}36 \\
\mathrm{U} / \mathrm{L}\end{array}$ & 100 & 77 & --- & --- \\
\hline $\begin{array}{l}\text { Dave KK } \\
(2013)^{18}\end{array}$ & --- & $\begin{array}{c}60 \\
\mathrm{U} / \mathrm{L}\end{array}$ & 69.2 & 92 & 90 & 74 \\
\hline $\begin{array}{c}\text { Helmy NA } \\
(2012)^{19}\end{array}$ & $\begin{array}{c}83.5 \pm \\
50.3\end{array}$ & $\begin{array}{c}30 \\
\mathrm{U} / \mathrm{L}\end{array}$ & 80 & 85 & 84.2 & 81 \\
\hline $\begin{array}{l}\text { Chen ML } \\
(2004)^{20}\end{array}$ & --- & $\begin{array}{l}55.8 \\
\mathrm{U} / \mathrm{L}\end{array}$ & 87.3 & 91.8 & 82.1 & 94.4 \\
\hline $\begin{array}{l}\text { Sharma } \\
(2001)^{11}\end{array}$ & $\begin{array}{c}95.8 \pm \\
57.5\end{array}$ & $\begin{array}{c}35 \\
\mathrm{U} / \mathrm{L} \\
100 \\
\mathrm{U} / \mathrm{L}\end{array}$ & $\begin{array}{c}83.3 \\
40\end{array}$ & $\begin{array}{l}66.6 \\
100\end{array}$ & --- & --- \\
\hline $\begin{array}{l}\text { Mehta A } \\
(2014)^{21}\end{array}$ & $\begin{array}{c}64.11 \pm \\
32.33 \\
\end{array}$ & $\begin{array}{c}40 \\
\mathrm{U} / \mathrm{L}\end{array}$ & 85.7 & 80.8 & 75 & 89.5 \\
\hline $\begin{array}{l}\text { Nayak M } \\
(2017)^{22}\end{array}$ & $\begin{array}{c}84.99+ \\
45.45\end{array}$ & $\begin{array}{c}40 \\
\mathrm{U} / \mathrm{L}\end{array}$ & 90 & 96.67 & 96.43 & 90.62 \\
\hline $\begin{array}{c}\text { Riantawan P } \\
(1999)^{23}\end{array}$ & --- & $60 \mathrm{U} / \mathrm{L}$ & 95 & 96 & 96 & 95 \\
\hline $\begin{array}{c}\text { Yu YX } \\
(2010)^{24}\end{array}$ & --- & $\begin{array}{l}28.7 \\
\mathrm{U} / \mathrm{L}\end{array}$ & 75.5 & 95.2 & --- & --- \\
\hline Current Study & $\begin{array}{c}60.09 \pm \\
38.36\end{array}$ & $\begin{array}{l}38.3 \\
\mathrm{U} / \mathrm{L}\end{array}$ & 92.5 & 97 & 96 & 94 \\
\hline
\end{tabular}

\section{CONCLUSION}

The mean ADA values were significantly higher in tuberculous pleural effusions when compared to the non-tuberculous group. At the cut-off value of $38.3 \mathrm{U} / \mathrm{L}$, ADA had a sensitivity of $93 \%$ and specificity of $97 \%$ in diagnosing tuberculosis. The above value had the maximum Youden's index (0.89) also.

\section{REFERENCES}

[1] Valdes L, Alvarez D, San Jose E, et al. Tuberculous pleurisy: a study of 254 patients. Arch Intern Med 1998;158(18):2017-21.

[2] Liang QL, Shi HZ, Wang K, et al. Diagnostic accuracy of adenosine deaminase in tuberculous pleurisy: a metaanalysis. Respir Med 2008;102(5):744-54.

[3] Greco S, Girardi E, Masciangelo R, et al. Adenosine deaminase and interferon gamma measurements for the diagnosis of tuberculous pleurisy: a meta-analysis. Int J Tuberc Lung Dis 2003;7(8):777-86.

[4] Gui X, Xiao H. Diagnosis of tuberculous pleurisy with ADA: a systematic review and meta-analysis. Int J Clin Exp Med 2014;7(10):3126-35.

[5] Light RW. Pleural diseases. $5^{\text {th }}$ edn. Philadelphia, PA: Lippincott Williams \& Wilkins 2007.

[6] Gupta B, Bharat V, Bandyopadhyay D. Role of adenosine deaminase estimation in differentiation of tuberculous and non-tuberculous exudative pleural effusions. J Clin Med Res 2010;2(2):79-84.

[7] Gopi A, Madhavan SM, Sharma SK, et al. Diagnosis and treatment of tuberculous pleural effusion in 2006 Chest 2007;131(3):880-9.

[8] Sahn SA. State of the art. The pleura. American Rev Resp Dis 1988;138(1):184-234.

[9] Berger HW, Mejia E. Tuberculous pleurisy. Chest 1973;63(1):88-92.

[10] Tay TR, Tee A. Factors affecting pleural fluid adenosine deaminase level and the implication on the diagnosis of tuberculous pleural effusion: a retrospective cohort study. BMC Infectious Diseases 2013;13:546.

[11] Sharma SK, Suresh V, Mohan A, et al. A prospective study of sensitivity and specificity of adenosine deaminase estimation in the diagnosis of tuberculous pleural effusion. Indian $\mathrm{J}$ Chest Dis Allied Sci 2001;43(3):149-55.

[12] Rahman MF, Zafar E, Prasad KR, et al. Study of ADA and lymphocyte/neutrophil ratio in combination as diagnostic tool for tubercular pleural effusion. J Evolution Med Dent Sci 2015;4(88):15356-9.

[13] Burgess LJ, Maritz FJ, Le Roux I, et al. Combined use of pleural ADA with lymphocyte/neutrophil ratio. Increased specificity for the diagnosis of tuberculous pleuritis. Chest 1996;109(2):414-9.

[14] Antin SS, Kashinkunti M, Darsana R, et al. Use of pleural fluid lymphocyte neutrophil ratio in addition to pleural fluid ADA for the diagnosis of tuberculous pleural effusion. Sch J App Med Sci 2014;2(2A):498-501.

[15] Shin MK, Ham HS, Lee DW, et al. The diagnostic usefulness of pleural fluid adenosine deaminase lymphocyte/neutrophil ratio in tuberculous pleural effusion. Tuberc Respir Dis 2004;57(2):132-7. 
[16] Valdes L, San Jose ME, Pose A, et al. Diagnosing tuberculous pleural effusion using clinical data and pleural fluid analysis: a study of patients less than 40 years-old in an area with a high incidence of tuberculosis. Respir Med 2010;104(8):1211-7.

[17] Verma SK, Dubey AL, Singh PA, et al. Adenosine deaminase (ADA) level in tubercular pleural effusion. Lung India 2008;25(3):109-10.

[18] Dave KK, Mehta NV, Gonsai RN, et al. Diagnostic significance of ADA in tuberculous pleural effusion. Int J Cur Res Rev 2013;6(1):69-71.

[19] Helmy NA, Eissa SA, Masoud HH, et al. Diagnostic value of ADA in tuberculous and malignant pleural effusion. Egyptian Journal of Chest Diseases and Tuberculosis 2012;61(4):413-7.
[20] Chen ML, Yu WC, Lam CW, et al. Diagnostic value of pleural fluid ADA activity in tuberculous pleurisy. Clin Chim Acta 2004;341(1-2):101-7.

[21] Mehta AA, Gupta AS, Ahmed S, et al. Diagnostic utility of ADA in exudative pleural effusions. Lung India 2014;31(2):142-4.

[22] Nayak M, Jayantibhai SA, Significance of ADA level in diagnosis of tuberculous pleural effusion. J Evolution Med Dent Sci 2017;6(75):5340-4.

[23] Riantawan P, Chaowalit P, Wongsangiem $M$, et al. Diagnostic value of pleural fluid ADA in tuberculous pleuritis with reference to HIV coinfection and a Bayesian analysis. Chest 1999;116(1):97-103.

[24] Yu YX. Zhonghua Jie He He Hu Za Zhi. 2010;33(4):2735. 